\title{
Simulation and Implementation of a Modified ANFIS MPPT Technique
}

\author{
Bachar Meryem*, Naddami Ahmed, Fahli Ahmed \\ Department of Electrical Engineering, Hassan First University, Settat, Morocco \\ Received 19 Nobember 2019; received in revised form 06 March 2020; accepted 06 June 2020 \\ DOI: https://doi.org/10.46604/aiti.2020.4987
}

\begin{abstract}
The maximum power point tracking (MPPT) algorithms ensure optimal operation of a photovoltaic (PV) system to extract the maximum PV power, regardless of the climatic conditions. This paper exposes the study, design, simulation and implementation of a modified advanced neural fuzzy inference system (ANFIS) MPPT algorithm based on fuzzy data for a PV system. The studied system includes a PV array, a DC/DC buck converter, the ANFIS controller, a proportional-integral (PI) controller, and a load. The simulation and experimental tests are carried out with the MATLAB/Simulink software and LabVIEW, respectively. Moreover, the obtained results are compared with previously published results by incremental conductance (IC) and fuzzy logic (FL) algorithms under different climatic conditions of irradiation and temperature. The results show that the proposed ANFIS algorithm is able to track the maximum power point for varying climatic conditions. Furthermore, the comparison analysis reveals that the PV system using ANFIS algorithm has more efficient and better dynamic response than FL and IC.
\end{abstract}

Keywords: PV panel, MPPT algorithm, Buck converter, ANFIS

\section{Introduction}

Nowadays, the demand for energy is constantly rising; however, the availability of fossil energy is rapidly declining. As a result, the cost of energy increasing becomes a hurdle to social development [1-2]. Solar energy with multiple benefits [3] is an effective solution to the production of green energy and also an alternative source. One of the most important solar technologies is photovoltaic (PV), which comes from converting sunlight into electricity within semiconductor materials such as silicon under the PV effect [4-5]. The association of the PV cells gives a PV panel that produces direct electrical energy. It can be stored in batteries or injected into the network. Hence, PV panels can be used for a stand-alone and grid-connected system [6]. However, PV energy is unstable because of its dependence on the load impedance and climatic conditions such as irradiation and temperature [7-8]. The PV cell characteristic has only one point where the power is maximum called maximum power point (MPP) [9]. As a consequence, researchers are developing approaches to extract as much power as possible from PV panels.

Maximum power point tracking (MPPT) algorithms are used to extract the maximum power and improve the productivity of the PV system regardless of the change in climatic conditions. They are used to adjust the duty cycle (D) to a power conversion system, for example, DC/DC converters act as an impedance matching circuit between the PV array and the load [10-11]. Up to today, several MPPT algorithms have been used to rise above these problems. They can be classified according to the number of the used sensors, the cost, the complexity, and the efficiency.

* Corresponding author. E-mail address: meryem.bachar@gmail.com Tel.: +2126501753; Fax: +212(0)523490354 
There are two types of MPPT techniques. First, the conventional MPPT techniques like the perturb and observe (P\&O) [12-13], incremental conductance (IC) [14-15], the look-up table [16] Second, the intelligent MPPT techniques such as fuzzy logic (FL) [17], the fuzzy logic type 2 (FLT2) [18], neural network (NN) [19], and advanced neural fuzzy inference system (ANFIS).

NN and FL systems are universal intelligent approximators. NNs have an interesting learning ability, while FL systems are built from human knowledge and have a high capacity for description through its use of linguistic values. These advantages have suggested a hybrid solution that combines the two cited approximators: FL and NN algorithm. This hybrid solution can be called a neuro-fuzzy approach or the ANFIS approach.

In general, the used output power of the PV panel in the ANFIS system is obtained after monitored the behavior of the PV panel in different climatic conditions for a long time. The objective of this paper is to predict the power of the PV panel by the FL algorithm simulations and use the obtained data in the proposed ANFIS system to make up for the lost time.

In this study, the ANFIS MPPT algorithm was used to extract the MPP from the PV array with a PI controller based on the fuzzy data. The authors tested the performance of the proposed algorithm and compared the simulation and experimental results using MATLAB/Simulink environment and laboratory virtual instrument engineering workbench (LabVIEW) software. The obtained results will be compared by the FL and IC MPPT algorithms results used in the previously published papers. To expose that, this paper is arranged as follows: The second section presents an electrical model of the PV cell that was used in the simulation and the effect of irradiation and temperature on the PV array. The third part gives details about the DC/DC converters, especially DC/DC buck ones. The fourth part shows the ANFIS MPPT algorithm and explains the principle of operation of this proposed technique. The fifth section represents the simulation results with the MATLAB/Simulink environment. The sixth part displays the experimental results with the LabVIEW software and CompactRio. Finally, the last part discusses and compares the results.

\section{Photovoltaic Cell}

A solar cell is a basic element in the PV system. It converts the incident light into electrical energy. To model a photovoltaic (PV) panel, it is the most important to model a PV cell [20]. Generally, the PV cell is presented by four elements: a current generator $\mathrm{I}_{\mathrm{ph}}$, a diode $\mathrm{D}$, a parallel resistance $\mathrm{R}_{\mathrm{sh}}$, and a series resistance Rs. $\mathrm{I}_{\mathrm{ph}}$ models the conversion of light radiation into electricity. D represents the PN junction. $\mathbf{R}_{\mathrm{sh}}$ symbolizes the leakage current and Rs models the internal losses due to connections between cells. Fig. 1 presents the equivalent circuit of the PV cell.

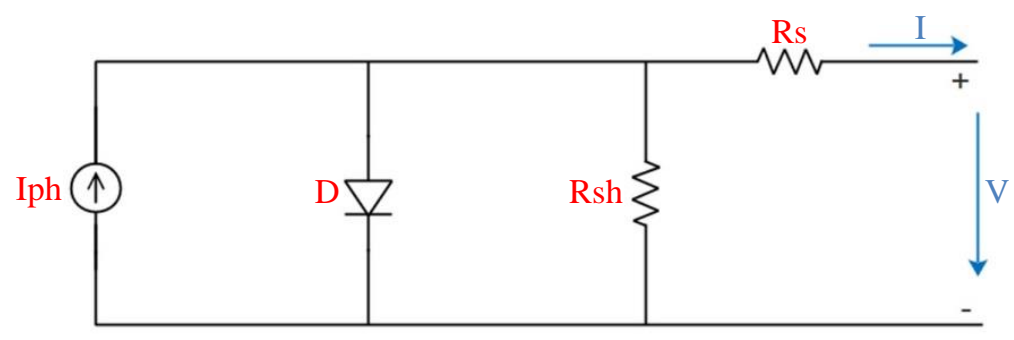

Fig. 1 The equivalent circuit of PV cell

The current generated by the solar cell is obtained by Eqs. (1)-(2):

$$
\begin{aligned}
& I=I_{p h}-I_{D}-I_{s h} \\
& I=I_{p h}-I_{0} \cdot e^{q\left(\frac{V+I R_{s}}{R_{s h}}\right)}-\frac{V+I R_{s}}{R_{s h}}
\end{aligned}
$$


$I_{p h}, I_{0}$, and $q$ are the photodiode current, the inverse saturation current, the charge of the electron, the ideality factor of the PN junction, the Boltzmann constant, and the temperature of the PV cell, respectively.

The PV cell generates only 0.6V. Consequently, the PV cells are connected in series or (and) in parallel to gain the desired voltage to supply the load. Figs. 2-3 indicate the I-V and P-V curve of the used PV array at $1000 \mathrm{~W} / \mathrm{m}^{2}$ and $30^{\circ} \mathrm{C}$.

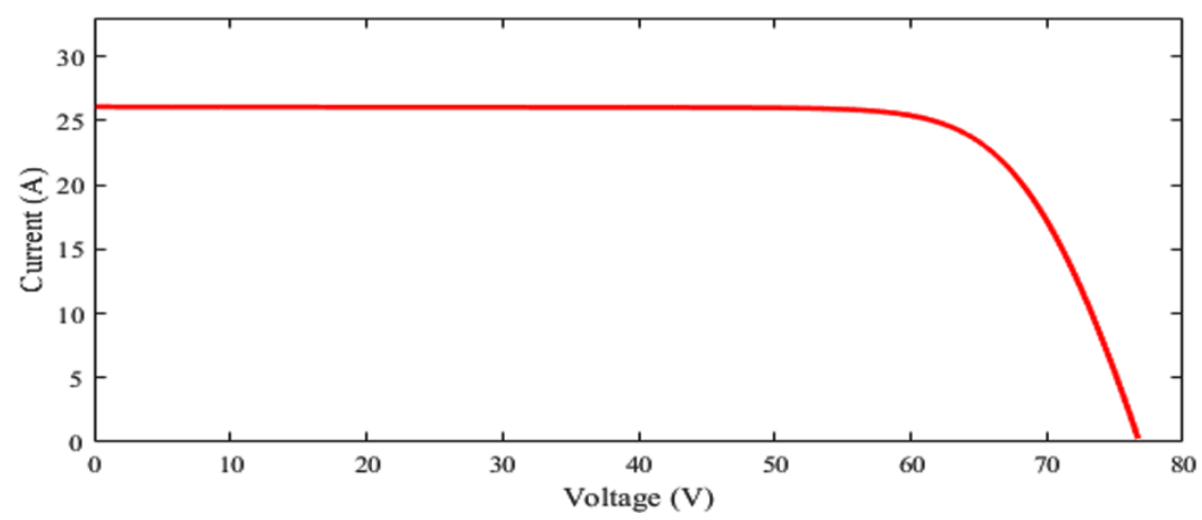

Fig. 2 I-V curve of the studied PV array

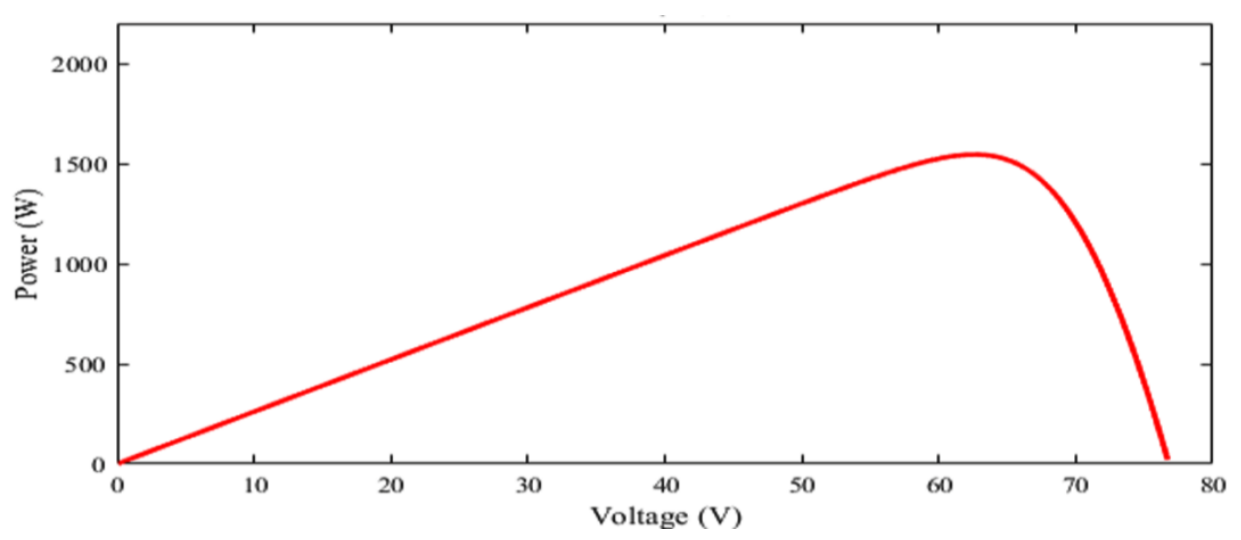

Fig. 3 P-V curve of the studied PV array

The characteristic of the PV array is influenced by climatic conditions such as irradiation and temperature. Fig. 4 shows the I-V and P-V curves of the used PV array for variant irradiation.

Fig 5 shows the PV characteristics for variant temperature during 0 and $75{ }^{\circ} \mathrm{C}$. In Figs. 4-5, it is seen that the current is produced by the PV panels increases when the irradiation increases. However, the voltage increases when the temperature decreases.

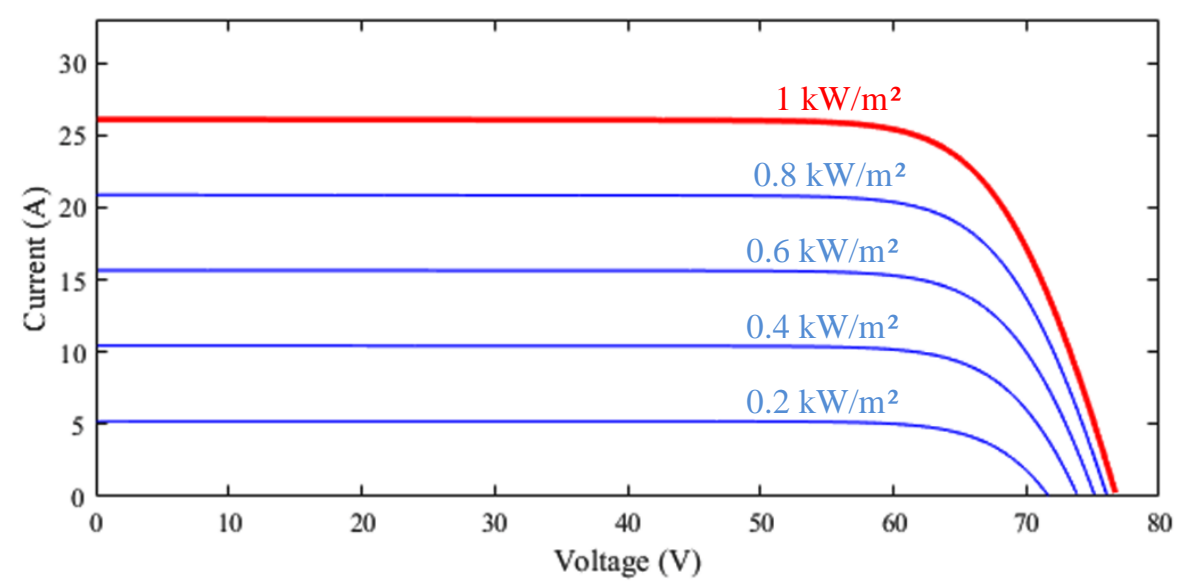

(a) I-V curves of the PV array

Fig. $4 \mathrm{I}-\mathrm{V}$ and P-V curve of the PV array for variant irradiation and constant temperature 


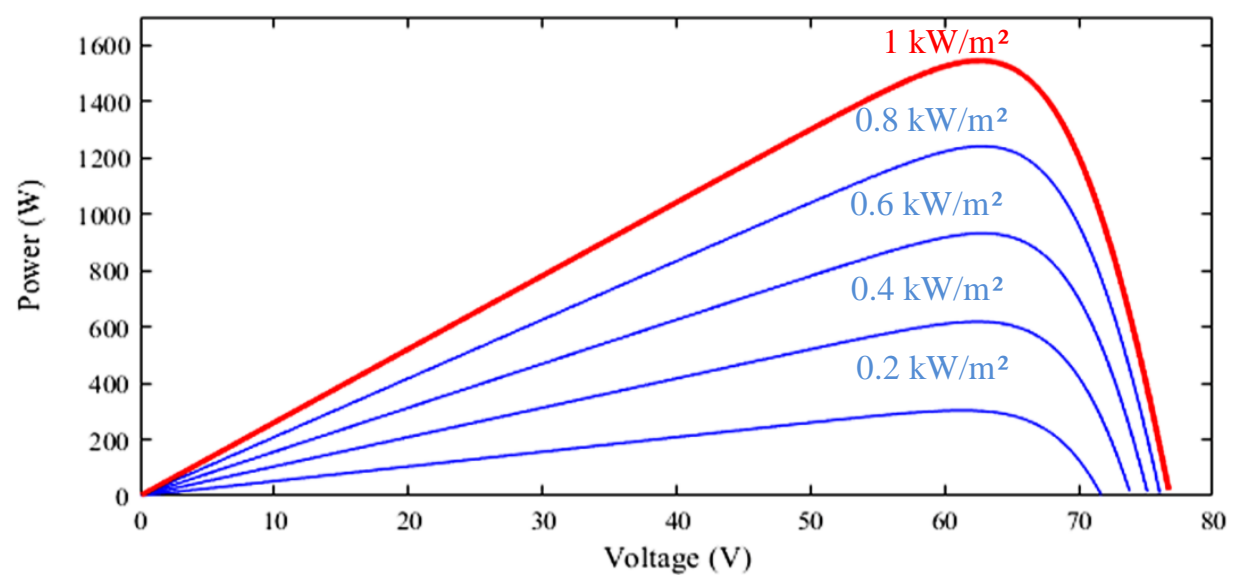

(b) P-V curves of the PV array

Fig. $4 \mathrm{I}-\mathrm{V}$ and P-V curve of the PV array for variant irradiation and constant temperature (continued)

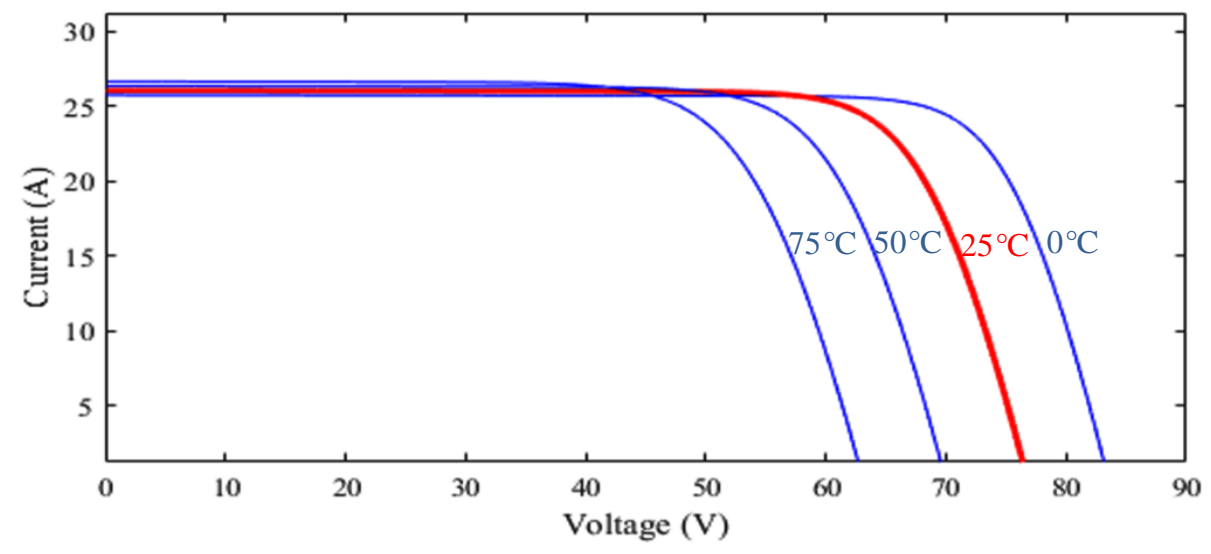

(a) I-V curves of the PV array

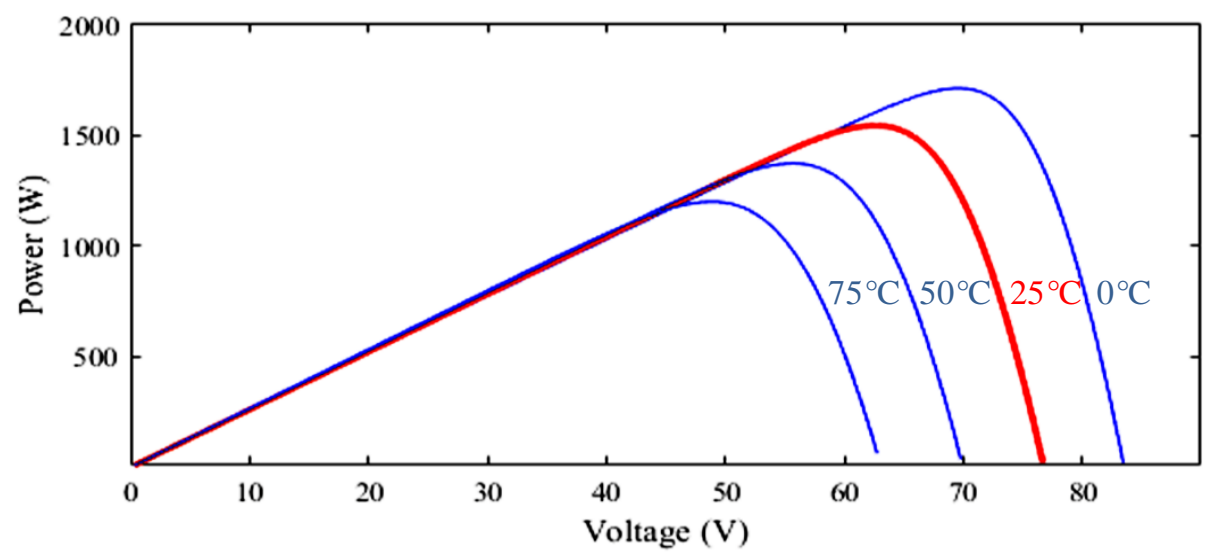

(b) P-V curves of the PV array

Fig. $5 \mathrm{I}-\mathrm{V}$ and $\mathrm{P}-\mathrm{V}$ curve of the PV array for variant temperature and constant irradiation

\section{A DC/DC Converter}

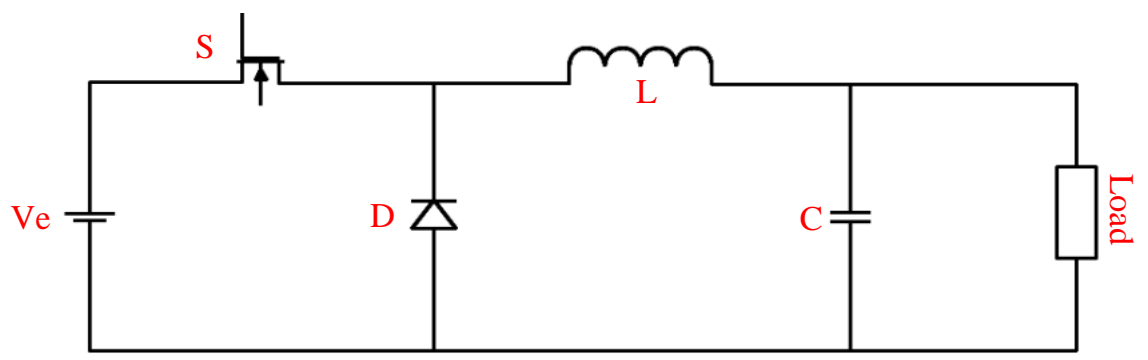

Fig. 6 The DC/DC Buck converter 
A DC/DC converter is used to transform the DC voltage supplied by the PV panel into a DC voltage suitable for supplying DC voltage receivers. Currently, different types of DC/DC converters are used such as the buck converter, the boost converter, the buck-boost converter, and the Full-bridge converter [21]. In this study, the buck converter is used to diminish output voltage as shown in Fig. 6.

The $\mathrm{V}_{\mathrm{e}}$ is the input voltage, $\mathrm{S}$ is a metal-oxide-semiconductor field-effect transistor (MOSFET) controlled by the MPPT controller, $\mathrm{D}$ is a diode, $\mathrm{L}$ is inductance, and $\mathrm{C}$ is a capacitor. When the switch $\mathrm{S}$ is closed, the voltage across the inductor is given by:

$$
V_{L}=V_{e}-V_{s}
$$

The relationship between the input voltage and the output voltage of the buck converter can be found by:

$$
V_{s}=D V_{e}
$$

where $\mathrm{D}$ is the duty cycle with $0<\mathrm{D}<1$.

\section{Adaptive Neuro-Fuzzy Inference System MPPT}

Maximum power point tracking (MPPT) algorithms are needed to extract the maximum power and improve the productivity of the PV system regardless of the change in climatic conditions. Several intelligent MPPT techniques exist such as NN, FL, and ANFIS.

The advanced neural fuzzy inference system (ANFIS) approach is a hybrid and intelligent solution that relies on human reasoning. It combines two MPPT techniques: NN and FL [22]. The learning mechanism of FL is based on conditional if-then rulescalled fuzzy rules. The main advantage of FL systems is the high capacity to interpret knowledge through its use of linguistic values. NNs get inspiration from the biological neurons of brain systems and mathematical learning theories.

ANFIS implemented a fuzzy inference system (FIS) of the type TAKAGI Sugeno (TSK). It had an architecture composed of five layers as shown in Fig. 7.

The studied system is characterized by two inputs and one output. It is based on a fuzzy model of the TSK type with the following two rules which are represented by an adaptive network [23].

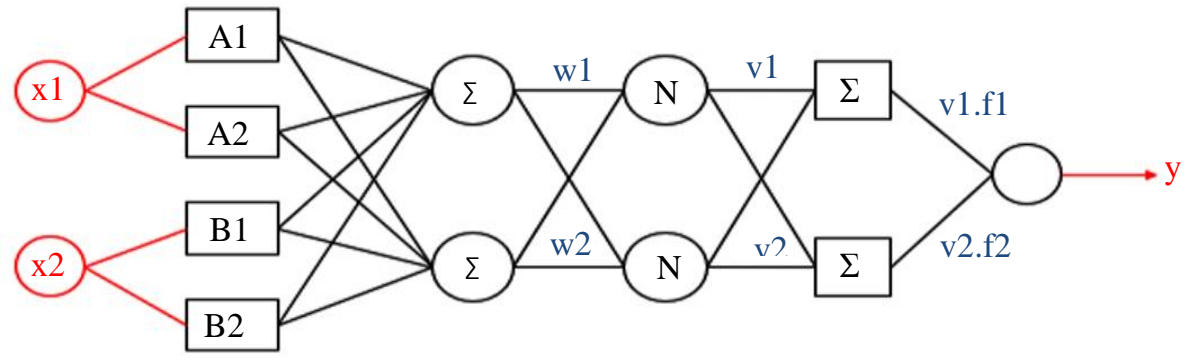

Fig. 7 ANFIS structure

The output is connected to the input by unweighted connections. Each node has different functionality and applies a function to the input signals. Square nodes are adaptive nodes that contain parameters, while circular nodes are fixed and do not contain parameters. Each node $\mathrm{i}$ of the layer $\mathrm{k}$ (node $(\mathrm{i}, \mathrm{n})$ ) has an output $O_{i}^{n}$ and depends on the signals of the layer $\mathrm{n}-1$ and the parameters of the node $(i, n)$ as presented in: 


$$
o_{i}^{n}=f\left(o_{i}^{k-1} \ldots o_{n k-1}^{k-1}, a, b, c \ldots\right)
$$

where the k-1 layer contains $\mathrm{n}_{\mathrm{k}-1}$ node. The $\mathrm{a}, \mathrm{b}$, c, etc., are the parameters about this node.

To understand how the ANFIS adaptive network works, it is recommended to understand how each layer works:

(1) Layer 1: In this layer, each neuron contributed to realize the fuzzy sets used in the antecedents of the rules. The model used in this work was Jan's model with Gaussian membership functions. The degree of membership $O_{i}^{1}$ is represented by:

$$
o_{i}^{1}=\mu_{A i}(x)
$$

where $\mathrm{x}$ is the input of the node $\mathrm{i}, \mu_{\mathrm{Ai}}$ is the membership function of the associated linguistic variable Ai.

(2) Layer 2: Each node received the outputs of fuzzification nodes to calculate its activation. The product of the equation made it possible to carry out the conjunction of the antecedents. The output $w_{\mathrm{i}}$ of this layer can be calculated by:

$$
w_{i}=\mu_{A i}\left(x_{1}\right) \cdot \mu_{B i}\left(x_{2}\right), i=1,2
$$

(3) Layer 3: The degree of truth $v_{\mathrm{i}}$ of a given fuzzy rule was calculated by the neurons as follows:

$$
v_{i}=\frac{w_{i}}{w_{1}+w_{2}}
$$

(4) Layer 4: During this layer, each neuron was connected to a normalization neuron and the initial inputs of the network. Neurons calculated the weighted consequence $O_{i}^{4}$ of the rule by Eq. (9):

$$
o_{i}^{4}=v_{i} \cdot f_{i}=v_{i}\left(a_{i} \cdot x_{1}+b_{i} \cdot x_{2}+c_{i}\right), i=1,2
$$

where vi is the output of Layer 3, and $\mathrm{f}_{\mathrm{i}}$ is the first-order polynomial.

(5) Layer 5: A single final neuron calculated the sum of the outputs of the defuzzification neurons to deliver the y ANFIS output:

$$
o_{i}^{5}=y=\sum_{i=1}^{n} v_{i} \cdot f_{i}
$$

Jan [24] proposed a hybrid learning solution based on a gradient descent algorithm with a least-square estimate. According to the FL data, the temperature and irradiation of the PV array are the inputs for the proposed ANFIS model which predicts the output PV power. At the same time, the actual power delivered by the PV array was calculated by measuring the voltage and current of the PV array. The actual power and predicted power by the ANFIS controller represent the input of the PI controller. The error was converted into an operating signal, which was then transformed into a PWM signal using a PWM generator. The PWM signal with a frequency of $25 \mathrm{KHz}$ controls the MOSFET of the DC/DC converter.

\section{Simulation Results}

The studied system was a PV installation equipped with an ANFIS controller. It mainly consists of a PV array, the DC/DC converter, an ANFIS controller, a PI regulator, and a load. The studied system on the MATLAB/Simulink software is shown in Fig. 8 . 


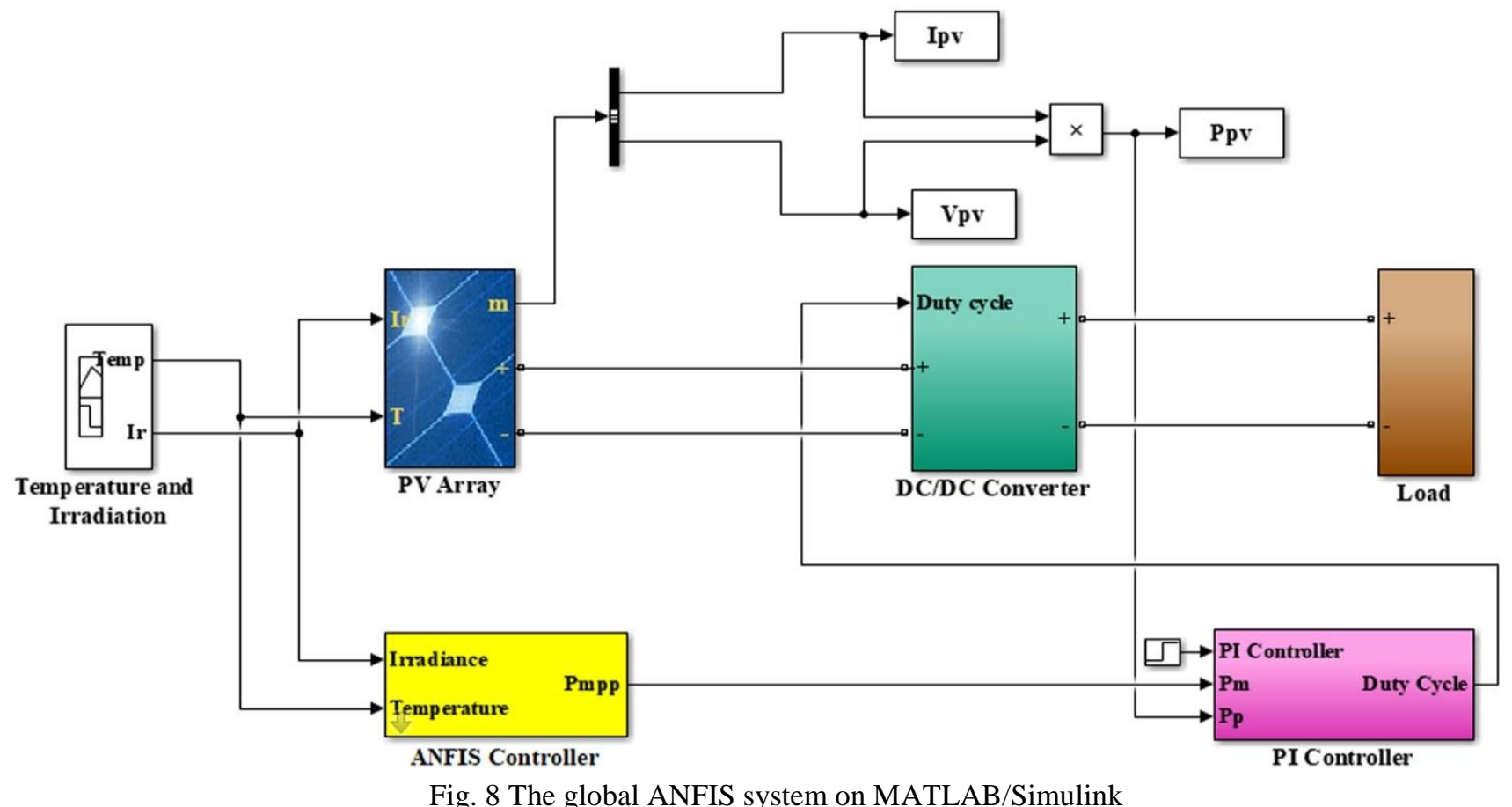

The PV array consists of six Tesla solar modules (Solar TS 255-P150-60). The PV module specifications given by the constructor are presented in Table 1 . All date was given for $1000 \mathrm{~W} / \mathrm{m}^{2}, 25^{\circ} \mathrm{C}$, and $1.5 \mathrm{AM}$.

Table 1 The Specifications of the PV Panel

\begin{tabular}{|c|c|}
\hline Description & Value \\
\hline Maximum Power $(\mathrm{W})$ & $255 \mathrm{~W}$ \\
\hline Maximum Power Current $(\mathrm{A})$ & $8.32 \mathrm{~A}$ \\
\hline Maximum Power Voltage $(\mathrm{V})$ & $30.6 \mathrm{~V}$ \\
\hline Short Circuit Current $(\mathrm{A})$ & $8.75 \mathrm{~A}$ \\
\hline Open Circuit Voltage $(\mathrm{V})$ & $37.6 \mathrm{~V}$ \\
\hline Shunt Resistor $(\Omega)$ & 529.6538 \\
\hline Series Resistor $(\Omega)$ & 0.29192 \\
\hline Module efficiency $(\%)$ & 15.58 \\
\hline Temperature Coefficient of Current in Short Circuit $\left(\% /{ }^{\circ} \mathrm{C}\right)$ & 0.0457 \\
\hline Temperature Coefficient of Voltage in Open Circuit $\left(\% /{ }^{\circ} \mathrm{C}\right)$ & -0.3538 \\
\hline Temperature Coefficient of Max Power $\left(\% /{ }^{\circ} \mathrm{C}\right)$ & -0.42 \\
\hline
\end{tabular}

The ANFIS controller developed in this paper comprises two inputs: irradiation (Ir) and temperature (T), as well as a single output power (OP), which indicated the optimal power predicted by the controller ANFIS as shown in Fig. 9. In this paper, the authors proposed a model of Sugeno inference for the generation of fuzzy rules ( 9 rules) in this controller.

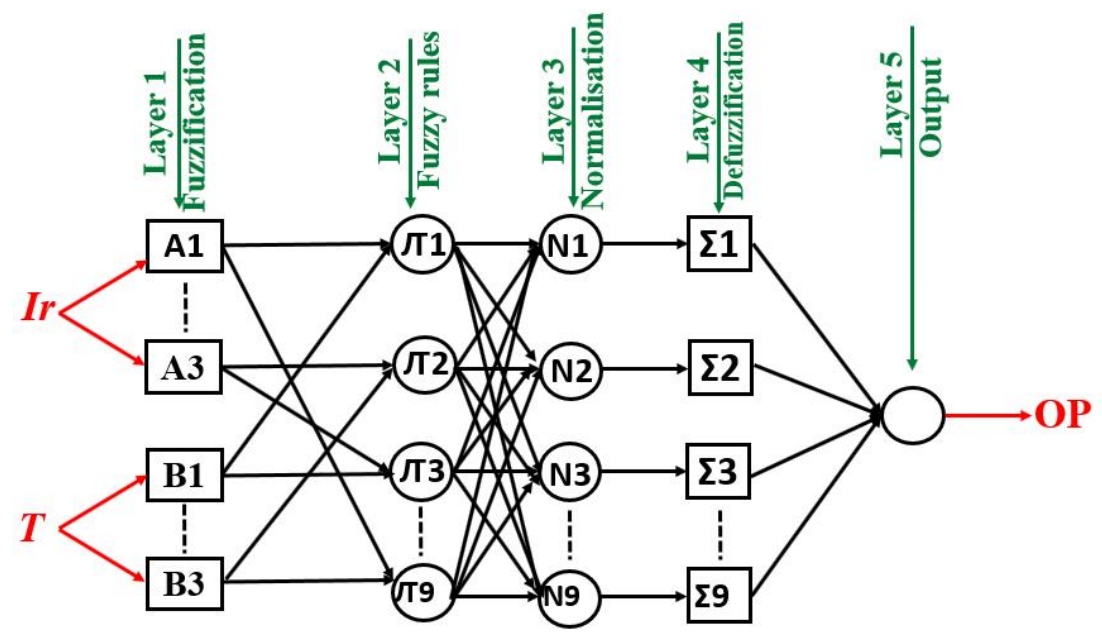

Fig. 9 ANFIS structure with MATLAB/Simulink 
The used data in the ANFIS regulator was obtained by FL prediction. The FL table contained different values of inputs (Ir and T). Each couple of inputs corresponds to an $\mathrm{OP}$ value. The temperature varied from $0^{\circ} \mathrm{C}$ to $60^{\circ} \mathrm{C}$ with a step of $5^{\circ} \mathrm{C}$, and the irradiation differed from $1 \mathrm{~W} / \mathrm{m}^{2}$ to $1300 \mathrm{~W} / \mathrm{m}^{2}$ with a pitch of $100 \mathrm{~W} / \mathrm{m}^{2}$. The simulation of the two varied factors gives a set of data of about 168 sets that are used to train the ANFIS controller.

Each input (Ir and T) has three membership functions which give nine fuzzy rules. To produce the maximum OP for each input, the rules were derived according to the input and output mapping. Fig. 10 shows the OP for one case of Ir and T level. When the irradiation is $655 \mathrm{~W} / \mathrm{m}^{2}$ and the temperature is $35^{\circ} \mathrm{C}$, the OP is $929 \mathrm{~W} / \mathrm{m}^{2}$.
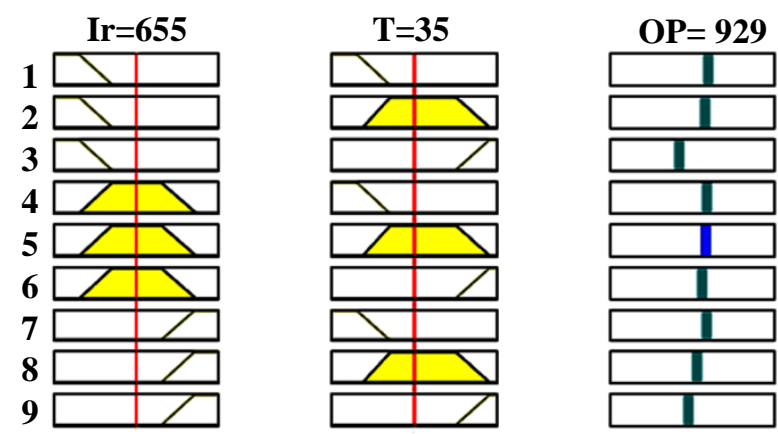

Fig. 10 ANFIS rules for specific values of Ir and T

To investigate the performance of the PV system, three scenarios were applied to the ANFIS MPPT system under MATLAB/Simulink.

\subsection{Constant irradiation and temperature}

The simulation of the global system with the ANFIS MPPT presented in Fig. 11 was done under uniform irradiation $\left(1100 \mathrm{~W} / \mathrm{m}^{2}\right)$ and fixed temperature $\left(30^{\circ} \mathrm{C}\right)$, which are similar to the real climatic conditions in the experimental tests.

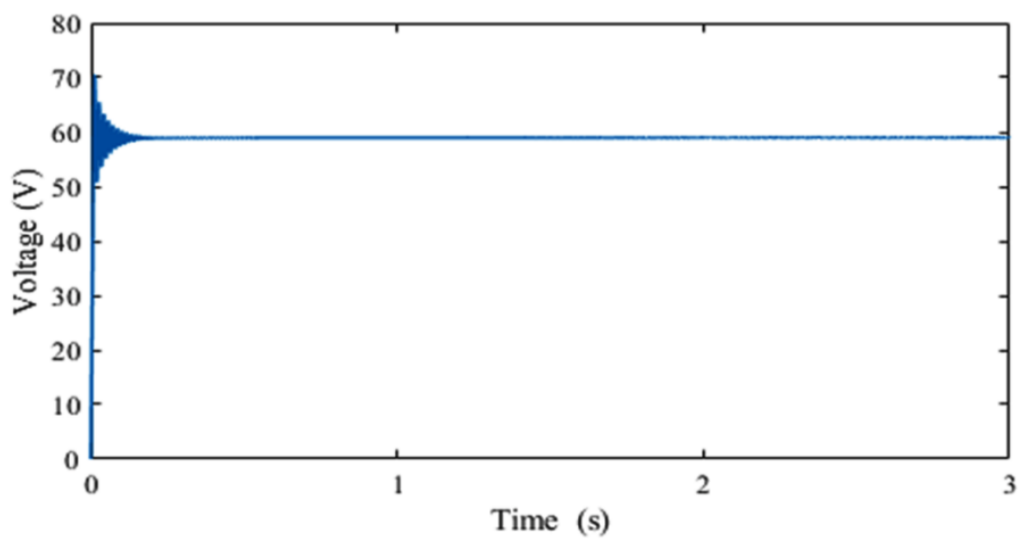

(a) PV voltage

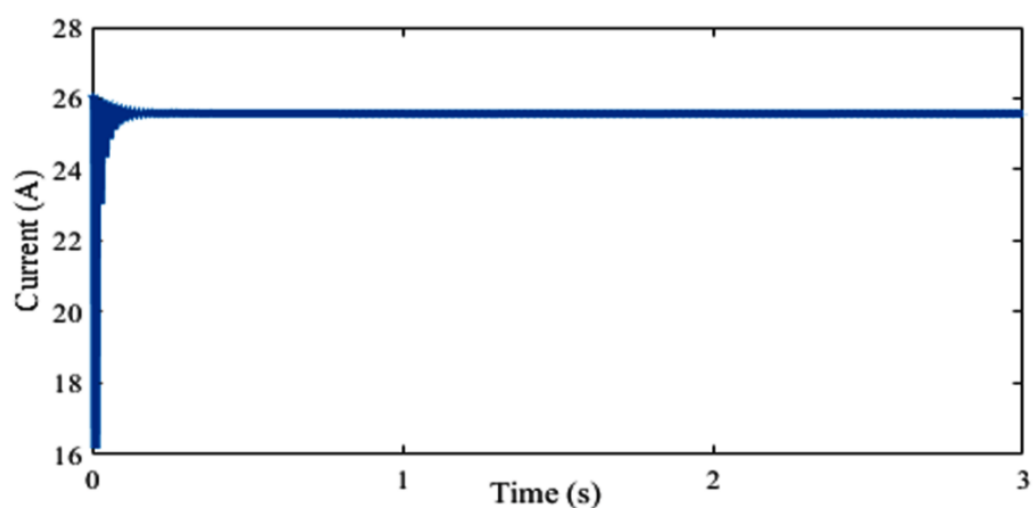

(b) PV current

Fig. 11 ANFIS MPPTalgorithm (stable climatic conditions) 


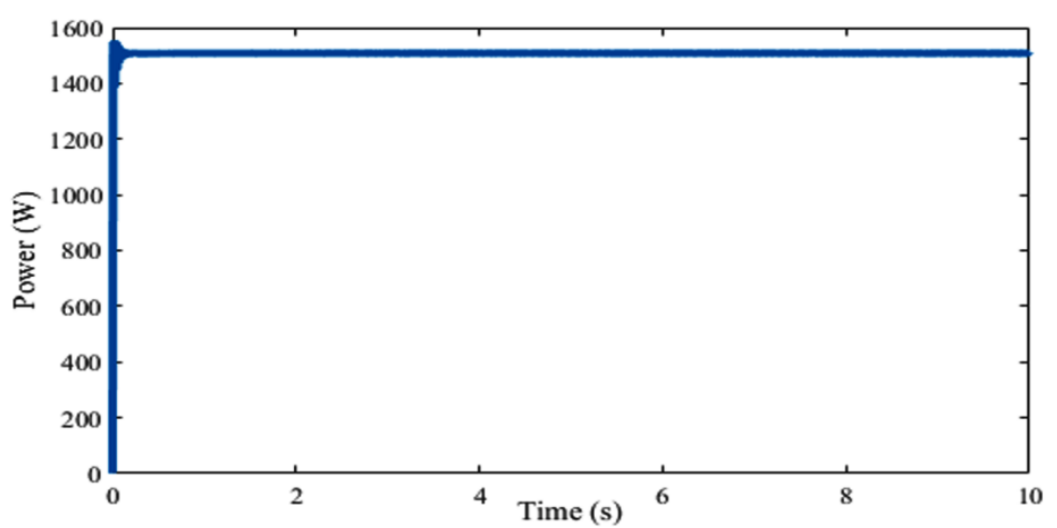

(c) PV power

Fig. 11 ANFIS MPPTalgorithm (stable climatic conditions) (continued)

T and Ir of the PV array were used as inputs of the ANFIS controller. Fig. 11 shows respectively the voltage, current, and power of the PV system. The voltage obtained by the ANFIS MPPT algorithm is $58.97 \mathrm{~V}$. The current is $25,58 \mathrm{~A}$, and the power is $1508 \mathrm{~W}$. The MPP is reached at $\mathrm{t}=0.20 \mathrm{~s}$. The curves are stable in the steady-state.

\subsection{Variable irradiation and constant temperature}

To verify the performance of the global system in different climatic conditions, non-uniform irradiation was applied to the input of the PV array. At the beginning of the simulation, the irradiation took $1100 \mathrm{~W} / \mathrm{m}^{2}$. After one second, it rapidly decreased to $250 \mathrm{~W} / \mathrm{m}^{2}$ and returned to $1100 \mathrm{~W} / \mathrm{m}^{2}$.

The simulation results show the voltage, current, and power curves generated by the PV array with the ANFIS MPPT algorithm in Fig. 12. After the rapid perturbation in irradiation, the ANFIS controller shows a better performance in terms of response time, stability, and OP. The variation of the irradiation influences the output PV current produced by the PV array, while the PV output voltage is slightly perturbed.

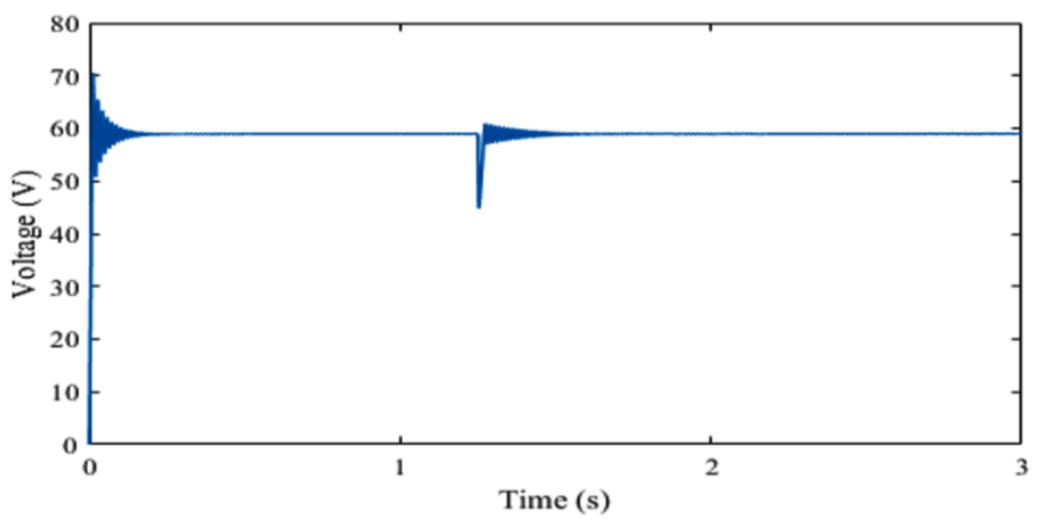

(a) PV voltage

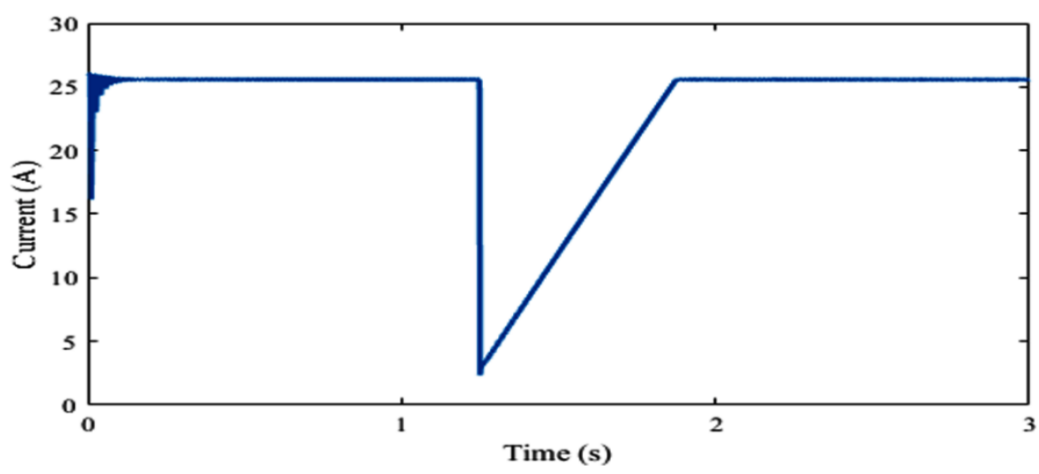

(b) PV current

Fig. 12 The ANFIS controller (variable irradiation) 


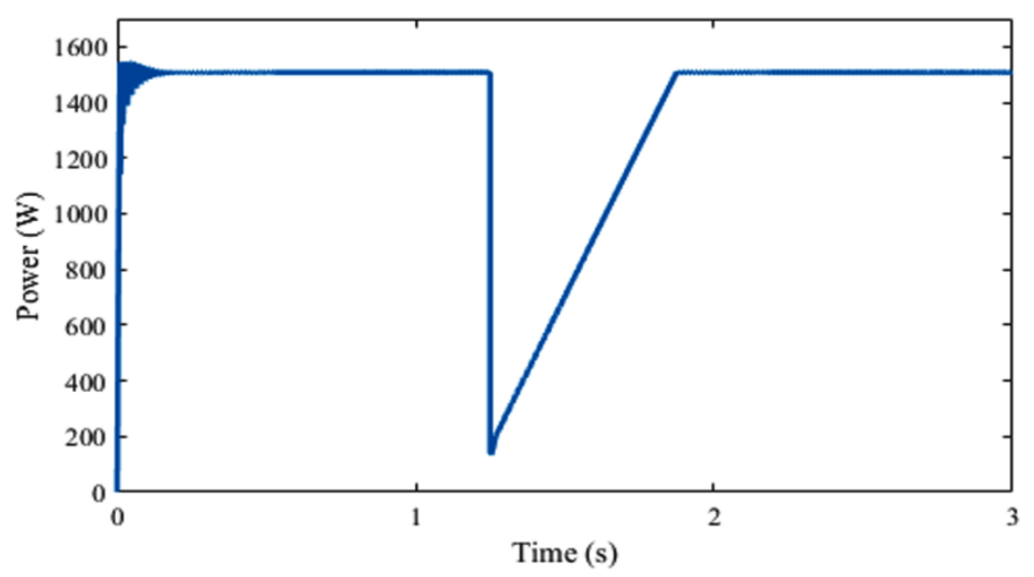

(c) PV power

Fig. 12 The ANFIS controller (variable irradiation) (continued)

\subsection{Constant irradiation and variable temperature}

To test the performance of the studied system with the modified ANFIS MPPT algorithm, the simulation of the global system with the ANFIS MPPT was done under constant irradiation $\left(1100 \mathrm{~W} / \mathrm{m}^{2}\right)$. The temperature was different from 30 to $45^{\circ} \mathrm{C}$ in one hour.

Fig. 13 reveals the simulation results in the case of variable temperature. It was observed that the voltage decreases when the temperature of the PV array decreases. While the temperature of the PV array is $30^{\circ} \mathrm{C}$, the output voltage is $58.66 \mathrm{~V}$. The temperature increases to $45^{\circ} \mathrm{C}$, then the output voltage decreases to $56.5 \mathrm{~V}$ as shown in Fig. 13 .

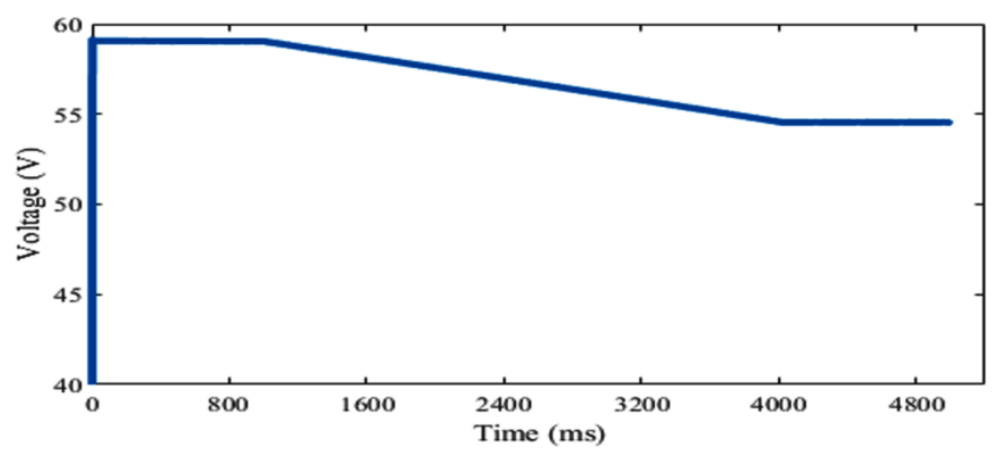

Fig. 13 The output PV voltage with the ANFIS controller (variable temperature)

The current varies from 24.78 to $24.46 \mathrm{~A}$ and the OP from 1508.4 to $1381.9 \mathrm{~W}$ as presented in Figs. 14-15. From the previous graphs, the simulations results proved that the proposed algorithm reaches MPP in the cases of variable temperature.

The previous tests confirmed that the proposed ANFIS MPPT algorithm reaches MPP without any perturbation. It had a good performance not only in the case of stable climatic conditions, but also in the case of variable irradiation and temperature.

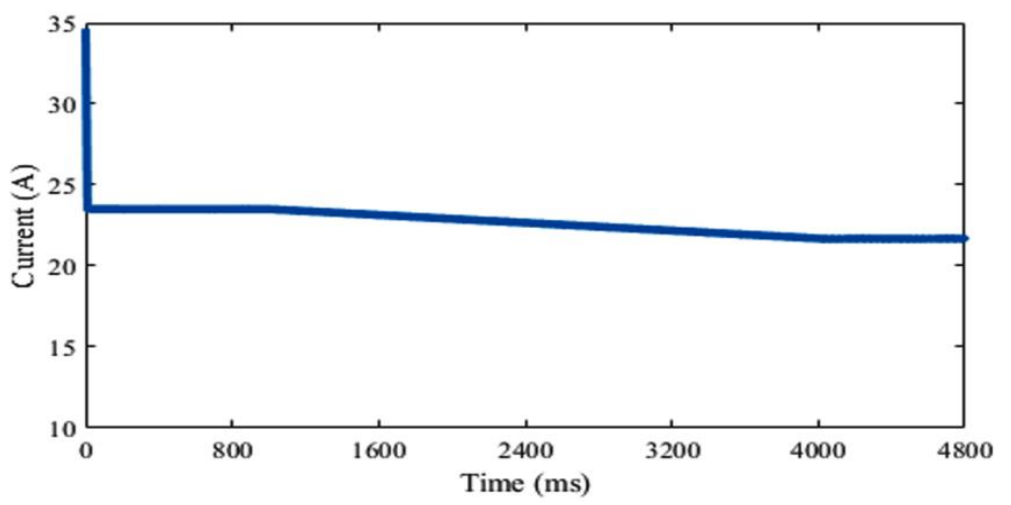

Fig. 14 The output PV current with the ANFIS controller (variable temperature) 


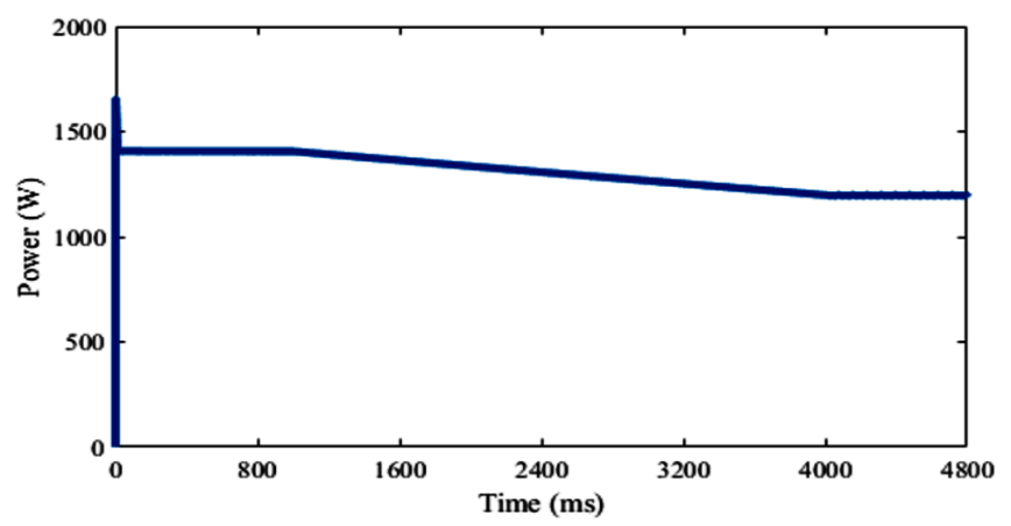

Fig. 15 The output PV power with the ANFIS controller (variable temperature)

\section{Experimental Test}

To prove the performance of the proposed MPPT technique practically, an experimental setup was installed. The diagram of the PV process is presented in Fig. 16.

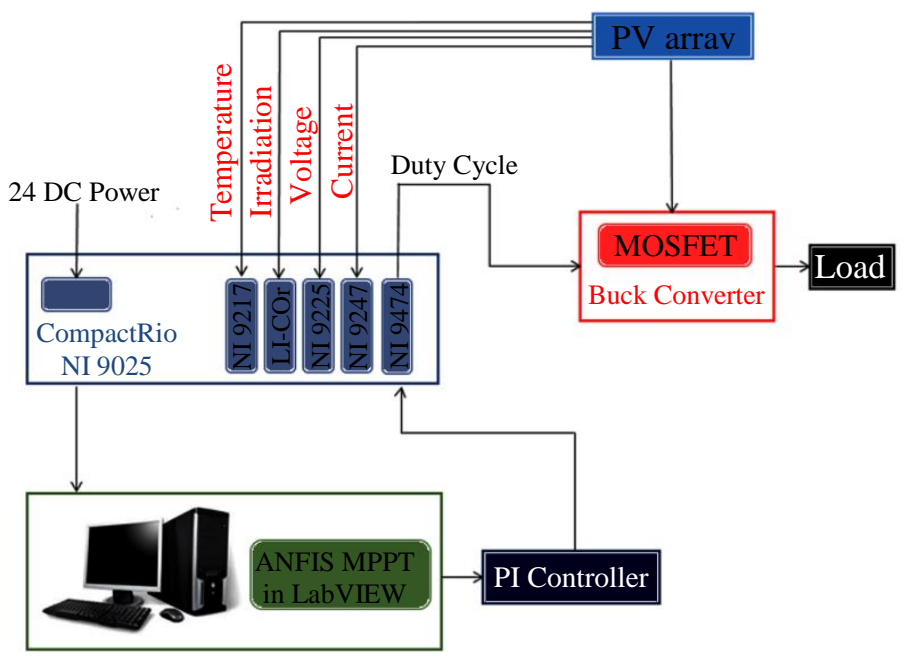

Fig. 16 Diagram of the PV process

In the experimental bench, six PV modules (solar TS255-P150-60) were connected to the DC/DC buck converter and then to the load. The temperature was sensed by the NI 9217 module $(0 \Omega$ to $400 \Omega$, PT100 RTD C Series Temperature Input Module) and the irradiation by using LI-COR light sensors with NI wireless sensor networks (WSN).

The voltage and the current are measured by NI 9225 (analog input module, 300Vrms) and NI 9247 (analog input module, 50 Arms), respectively. All collected data is given to the CompacRio NI 9025 from National Instruments, which controls MOSFET of the DC/DC buck converter using NI 9474 (Sourcing Digital Output, 5 to 30 V).

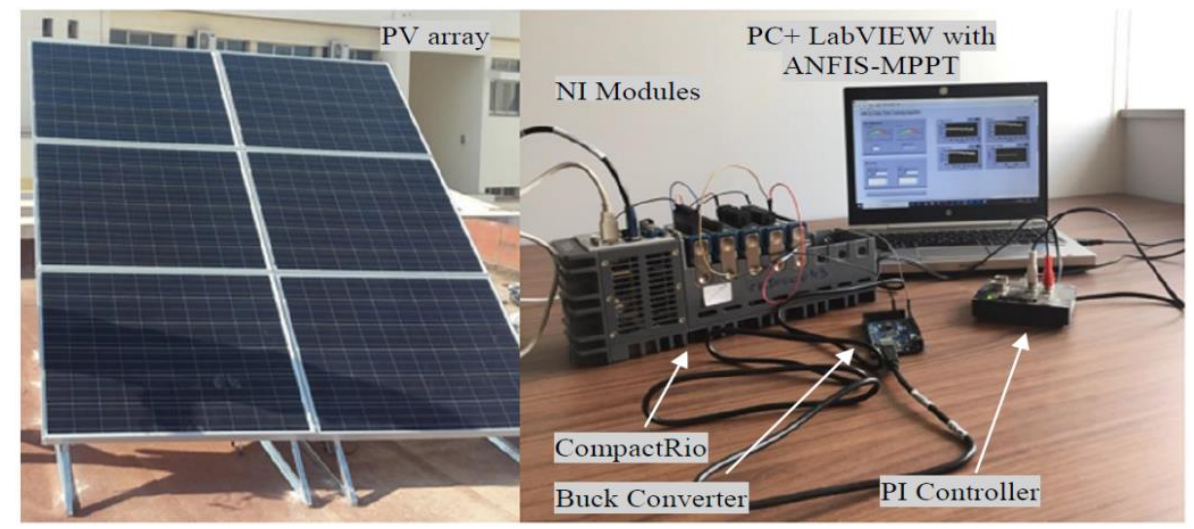

Fig. 17 Experimental setup with the PV array 
Fig. 17 exposes the hardware installation of the ANFIS MPPT system. The LabVIEW software was used in this work to program and implement the ANFIS MPPT algorithm. It is a graphical software from National Instruments, which dedicates to the system design, measurement, and control. The LabVIEW software is chosen thanks to its ease and flexibility of programming.

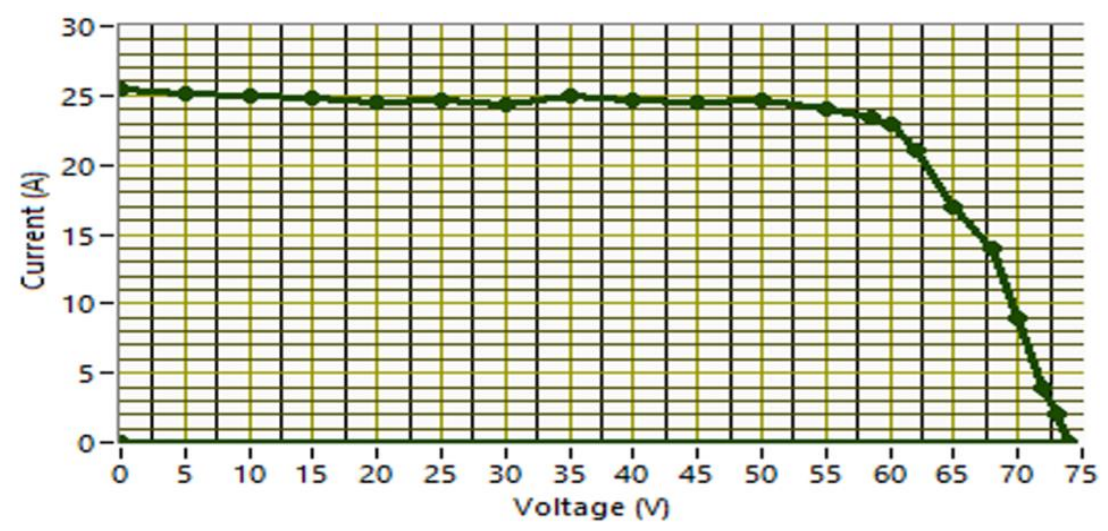

(a) I-V curve

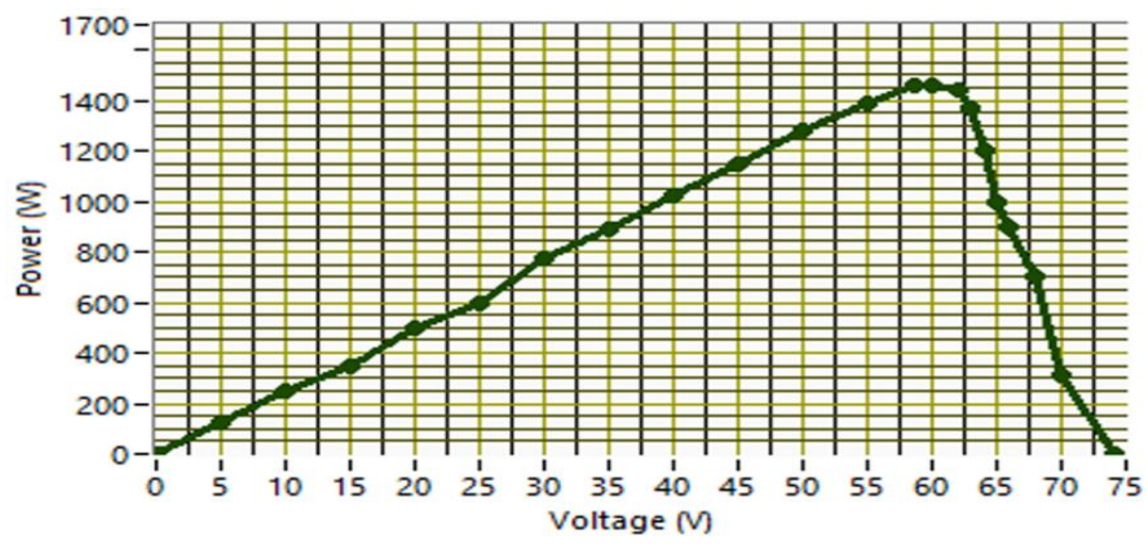

(b) P-V curve

Fig. $18 \mathrm{P}-\mathrm{V}$ and I-V curves of the PV array

The ANFIS MPPT algorithm is verified via the LabVIEW environment in the case of stable and variable climatic conditions. The experimental tests were done on August 29, 2019, on a sunny day. Fig. 18 presents the P-V and I-V curves of the PV array (6 solar TS255-P150-60) under $1100 \mathrm{~W} / \mathrm{m}^{2}$ and $30^{\circ} \mathrm{C}$. The experimental results are indicated in the figures below.

\subsection{Constant irradiation}

The experimental test of the PV system with the ANFIS MPPT algorithm was finished under constant irradiation $\left(1100 \mathrm{~W} / \mathrm{m}^{2}\right)$ and constant temperature $\left(30^{\circ} \mathrm{C}\right)$.

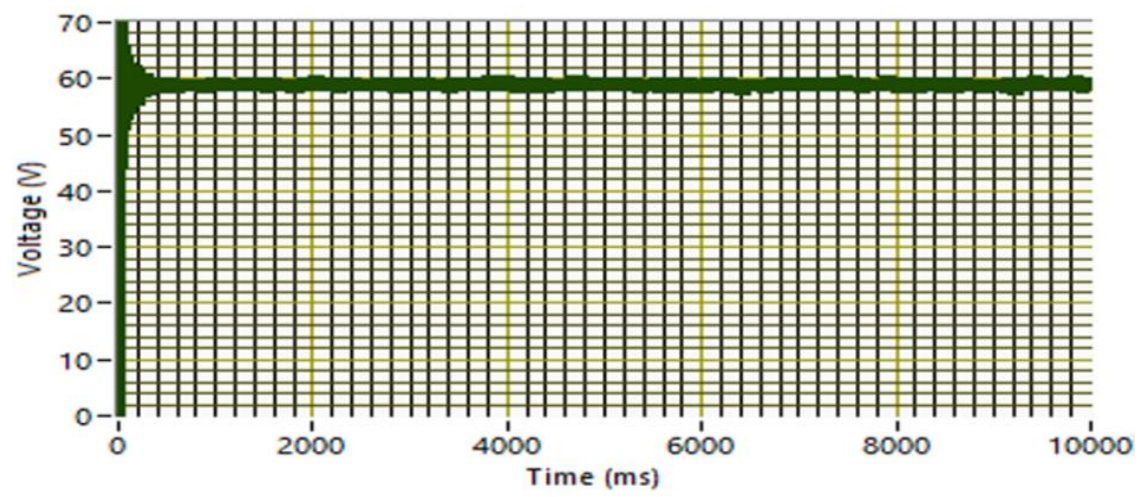

(a) Output PV voltage

Fig. 19 The experimental results with the ANFIS- MPPT algorithm in stable climatic conditions 


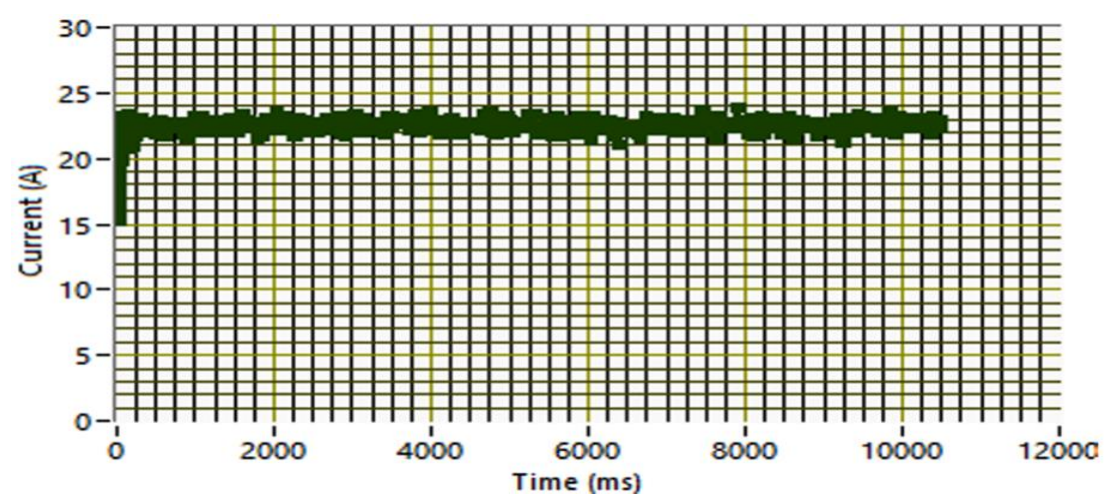

(b) Output PV current

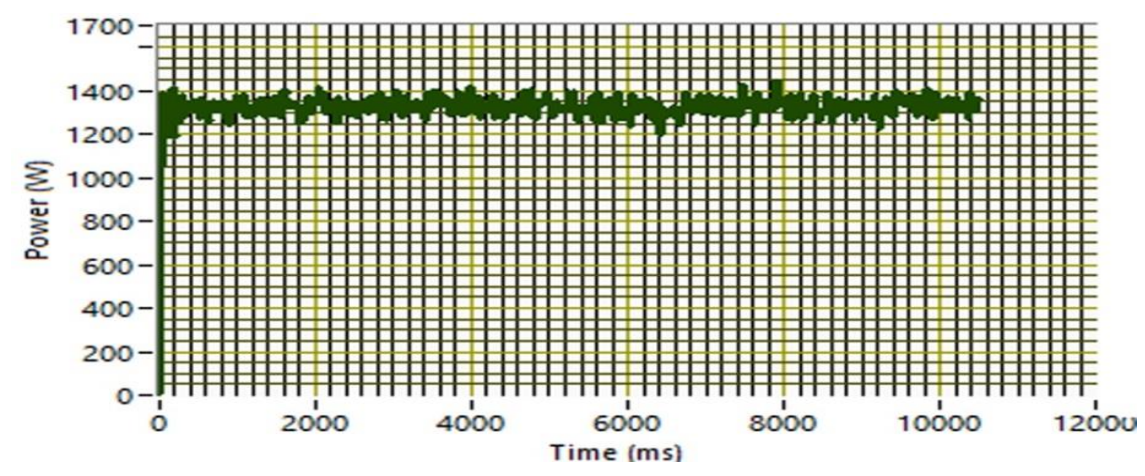

(c) PV OP

Fig. 19 The experimental results with the ANFIS- MPPT algorithm in stable climatic conditions (continued)

Fig. 19 shows the PV output current, the PV output voltage, PV OP, and the buck output voltage. The maximum power obtained by ANFIS MPPT is $1403 \mathrm{~W}$ at $\mathrm{t}=0.22 \mathrm{~s}$. The maximum output current is $23.93 \mathrm{~A}$ and the maximum voltage is $58.66 \mathrm{~V}$. When the MPP is reached, the power remains stable.

\subsection{Variable irradiation}

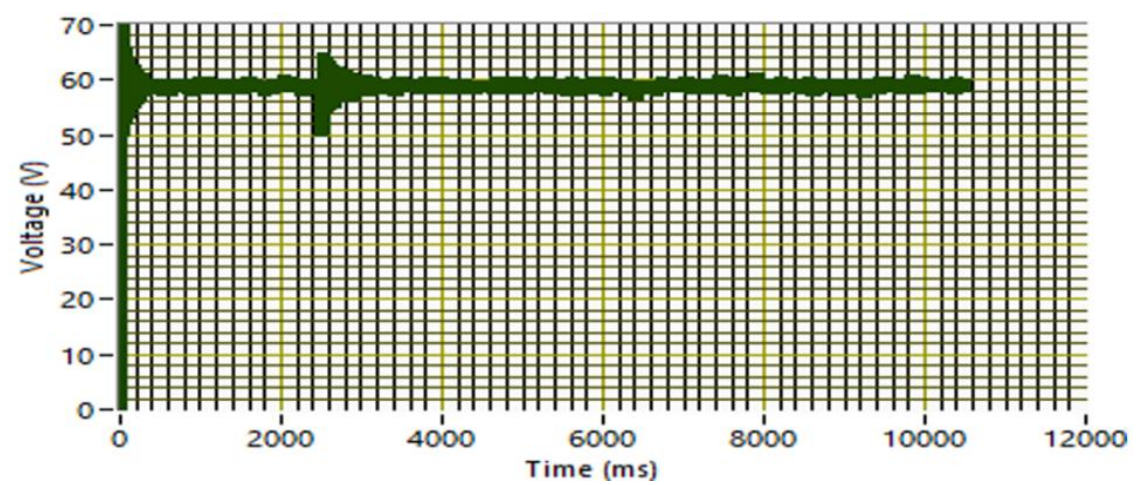

(a) Output PV voltage

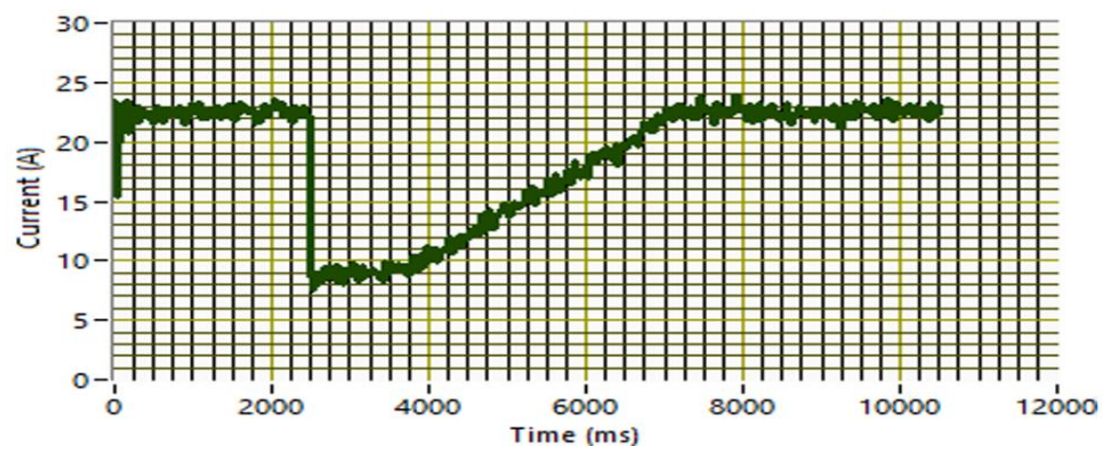

(b) Output PV current

Fig. 20 The experimental results with the ANFIS MPPT algorithm in variable irradiation (continued) 


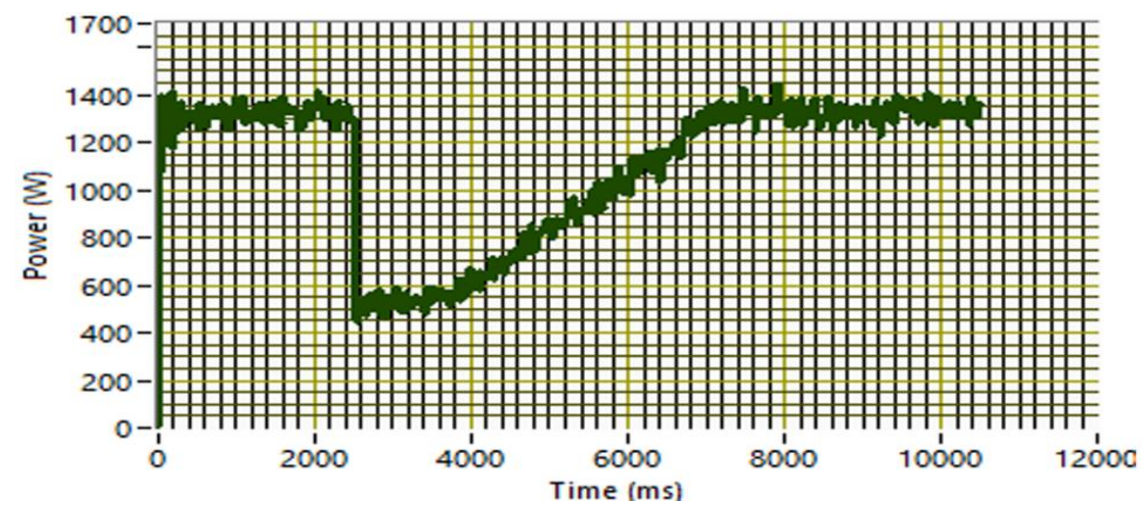

(c) PV OP

Fig. 20 The experimental results with the ANFIS MPPT algorithm in variable irradiation (continued)

In this part, a variation of the incidence angle of the irradiation was made to experiment the performance of the ANFIS MPPT algorithm in different climatic conditions. At the beginning of the test, the irradiation is equal to $1100 \mathrm{~W} / \mathrm{m}^{2}$. The power increases to $500 \mathrm{~W} / \mathrm{m}^{2}$ at $\mathrm{t}=3,2 \mathrm{~s}$ and then returns to the initial value.

Fig. 20 displays the experimental results. It can be seen that the curves retake easily MPP without falling the track. The power differs from $1403.73 \mathrm{~W}$ to $580 \mathrm{~W}$.

\subsection{Stable irradiation and variable temperature}

The experimental results are shown in Fig. 21. In the test, the temperature of the PV array is heavily increasing by using a heat exchanger from 30 to $45^{\circ} \mathrm{C}$ in 1 hour. The output current, voltage ,and power are mainly influenced by the variation of the temperature. The voltage increases to $55.7 \mathrm{~V}$, and the current is $22.5 \mathrm{~A}$ at the end of the test. The power varies from 1403.73 to 1253,25W. The results demonstrate that the proposed ANFIS MPPT shows fast response time and good performance of tracking in the case of variable temperature.

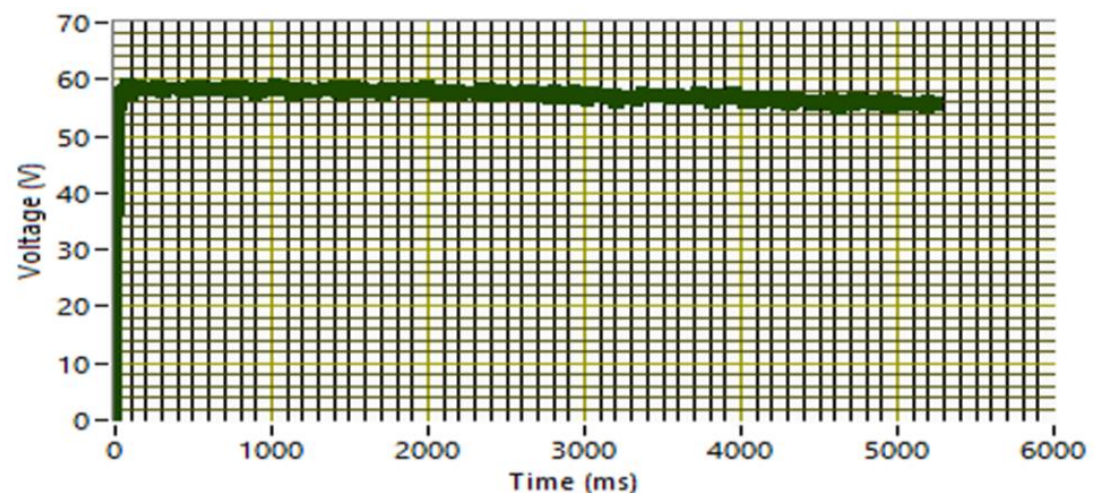

(a) Output PV voltage

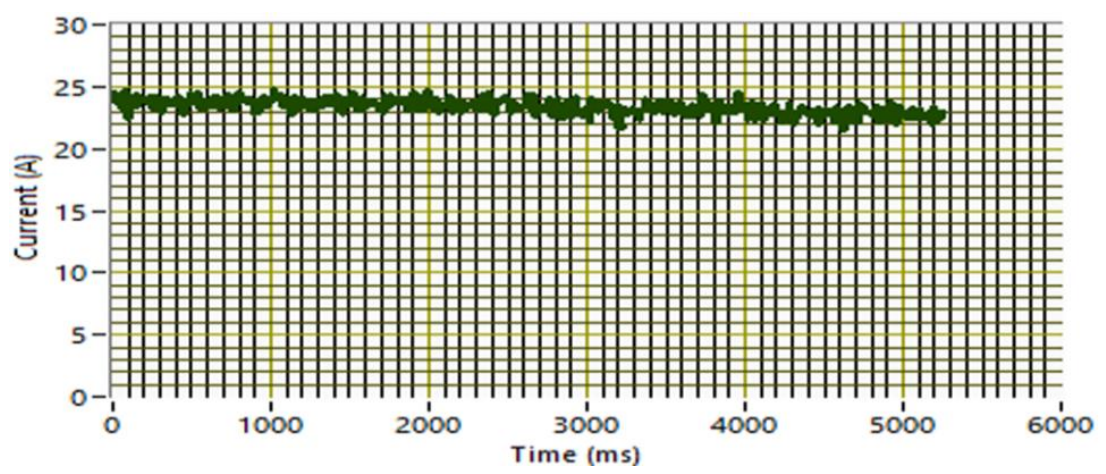

(b) Output PV current

Fig. 21 The experimental results with the ANFIS- MPPT algorithm in variable temperature 


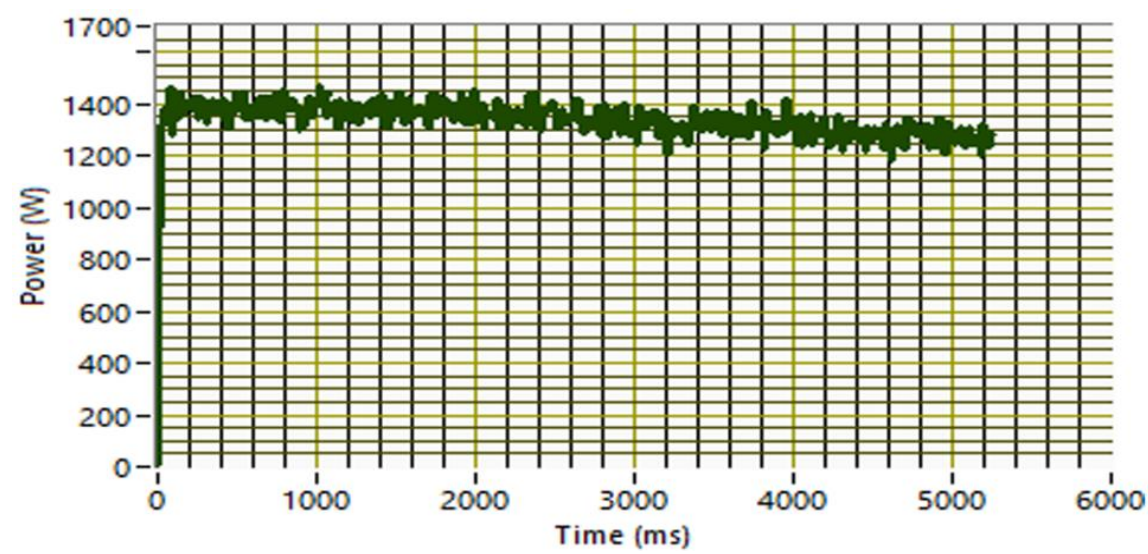

(c) OP PV

Fig. 21 The experimental results with the ANFIS- MPPT algorithm in variable temperature (continued)

\section{Discussion}

The simulation and experimental tests prove that the ANFIS MPPT algorithm can easily track MPP of the PV array. In the case of stable climatic conditions, the curves of the PV power, the PV current, and the PV voltage are very stable. In the variable climatic conditions, the ANFIS MPPT shows a good performance in tracking.

The ANFIS MPPT technique combines the high learning ability of the NNs and the important capacity for description through the FL systems of linguistic values. These advantages give ANFIS MPPT good performance.

The PV voltage, the PV current, the PV power, and the efficiency of the ANFIS MPPT technique, in the case of simulation and experience, are exposed in Table 2.

Table 2 Simulation and experimental results of ANFIS MPPT

\begin{tabular}{|c|c|c|}
\hline \multicolumn{3}{|c|}{ ANFIS MPPT Algorithm } \\
\hline Parameters & Simulation results & Experimental results \\
\hline PV Voltage (V) & 58.97 & 58.66 \\
\hline PV Current (I) & 25.58 & 23.93 \\
\hline PV Power (W) & 1508.4 & 1403.73 \\
\hline Efficiency (\%) & 97.58 & 94.39 \\
\hline
\end{tabular}

The efficiency $\eta_{\text {MPPT }}$ is calculated by:

$$
\eta_{M P P T}=\frac{P_{p v}}{P_{m p p}} \times 100
$$

where $\mathrm{P}_{\mathrm{pv}}$ is the measured output power of the PV panels, and $\mathrm{P}_{\mathrm{mpp}}$ is the maximum expected output PV power in the same conditions of $\mathrm{T}$ and Ir.

The efficiency of the proposed algorithm is $97.58 \%$ in the case of simulation, and $94.39 \%$ under the real experiment. The difference between the experimental test and simulation is justified by the losses in the conversion chain and the measurement instruments.

Table 3 Comparison of experimental and simulation results

\begin{tabular}{|c|c|c|}
\hline \multicolumn{3}{|c|}{ Efficiency (\%) } \\
\hline Parameters & Simulation results & Experimental results \\
\hline ANFIS & 97.58 & 94.39 \\
\hline Fuzzy Logic [13] & 96.26 & 94.14 \\
\hline Incremental Conductance [13] & 94.22 & 90.14 \\
\hline
\end{tabular}


Table 3 exposes the results of the simulation and experimental test of the PV system in previously published paper [13]. The research studies the IC and the FL MPPT algorithms by the same PV System used in this paper. It can be clearly realized that the efficiency of the ANFIS MPPT is better than the IC and FL MPPT techniques.

\section{Conclusions}

In this research, the design of a new ANFIS for MPPT based on the FL data and PI controller was proposed. The fuzzy data in the ANFIS MPPT algorithm was used to make up the lost time in the collection of the real data in classic ANFIS tests. The proposed technique was tested under two different climatic conditions: stable and variable $\mathrm{T}$ and Ir to show its performance.

In the simulation tests, MATLAB/Simulink software was used, while the acquisition and the control of the proposed ANFIS MPPT algorithm were made by the LabVIEW software and CompactRio NI 9032 hardware, respectively. The voltage, current, and power curves show high performance, efficiency and robustness of the proposed ANFIS MPPT algorithm under different cases of climatic conditions. The obtained results were compared to the previously published work with the same PV system.

The comparison analysis proved that the PV system using the proposed ANFIS algorithm was more efficient and robust than FL and IC MPPT algorithms in simulation and experimental tests. ANFIS is the method suggested for the application in physical structures, it presents lower energy losses. In addition, this method does not require the complete modeling of the system, thus it will be a solution for the difficult and complicated systems.

In future research, a balance should be observed between the costs of implementing a PV system, its performance, and profit for commercial applications. In addition, the studied MPPT algorithms can be tested in the case of a partial shading conditions of PV array and also for a grid-connected system.

\section{Conflicts of Interest}

The authors declare no conflict of interest.

\section{Table of abbreviation}

\begin{tabular}{|l|l|}
\hline$A$ & Ideality factor \\
\hline $\mathrm{A}_{\mathrm{i}}$ & Linguistic variable \\
\hline ANFIS & Adaptive Neuronal Fuzzy Inference System \\
\hline $\mathrm{D}$ & Duty Cycle \\
\hline $\mathrm{f}_{\mathrm{i}}$ & First order polynomial \\
\hline FIS & Fuzzy Inference System \\
\hline FL & Fuzzy Logic \\
\hline FLT2 & Fuzzy Logic Type 2 \\
\hline $\mathrm{i}$ & Node \\
\hline InC & Incremental Conductance \\
\hline $\mathrm{I}_{\mathrm{ph}}, \mathrm{I}_{\mathrm{D}}, \mathrm{I}_{\mathrm{sh}}$, and $\mathrm{I}_{0}$ & Photodiode current, Current diode, Rsh Current and Inverse saturation Current respectively \\
\hline $\mathrm{Ir}$ & Irradiation \\
\hline $\mathrm{K}$ & Boltzmann constant \\
\hline $\mathrm{k}$ & Layer \\
\hline MPP & Maximum Power Point \\
\hline $\mathrm{MPPT}$ & Maximum Power Point Tracking \\
\hline
\end{tabular}




\begin{tabular}{|l|l|}
\hline $\mathrm{NN}$ & Neural Networks \\
\hline$O_{i}^{n}$ & Degree of membership \\
\hline $\mathrm{OP}$ & Output Power \\
\hline $\mathrm{P} \& \mathrm{O}$ & Perturb and Observe \\
\hline $\mathrm{PI}$ & Proportional Integral \\
\hline $\mathrm{PV}$ & Photovoltaic \\
\hline $\mathrm{q}$ & Charge of electron \\
\hline $\mathrm{R}_{\mathrm{s}}$ & Series Resistance \\
\hline $\mathrm{R}_{\mathrm{sh}}$ & Parallel resistance \\
\hline $\mathrm{T}$ & Temperature of cell \\
\hline $\mathrm{TKS}$ & Takagi Sugeno \\
\hline$v_{\mathrm{i}}$ & Degree of truth \\
\hline $\mathrm{V}_{\mathrm{L}}, \mathrm{V}_{\mathrm{e}}$, and $\mathrm{V}_{\mathrm{s}}$ & Inductance voltage, input voltage and output voltage of the Buck converter \\
\hline$w_{\mathrm{i}}$ & Output of the Layer \\
\hline $\mathrm{x}$ & Input of the node \\
\hline$\mu_{\mathrm{Ai}}$ and $\mu_{\mathrm{Bi}}$ & Membership functions \\
\hline
\end{tabular}

\section{References}

[1] P. Srinivas, K. V. Lakshmi, and C. Ramesh, "Simulation of Incremental Conductance MPPT Algorithm for PV systems using Labview," International Journal of Innovative Research in Electrical, Electronics, Instrumentation and Control Engineering, vol. 4, no. 1, pp. 34-38, January 2016.

[2] A. Bouchakour, M. Brahimi, and A. Borni, "Comparative study on photovoltaic pumping systems driven by different motors optimized with sliding mode control," International Journal of Engineering and Technology Innovation, vol. 7, no. 3, pp. 201-216, January 2017.

[3] A. Nouaiti, A. Saad, A. Mesbahi, and M. Khafallah, "A new efficient topology of single-phase five-level inverter for PV system," International Journal of Engineering and Technology Innovation, vol. 8, no. 4, pp. 241-260, January 2018.

[4] S. Diwania, S. Agrawal, A. S. Siddiqui, and S. Singh, "Photovoltaic-thermal (PV/T) technology: a comprehensive review on applications and its advancement," International Journal of Energy and Environmental Engineering, November 2019.

[5] H. Bounechba, A. Bouzid, H. Snani, and A. Lashab, "Real time simulation of MPPT algorithms for PV energy system," Electrical Power and Energy System, vol. 83, pp. 67-78, December 2016.

[6] H. Shahid, M. Kamran, Z. Mehmood, M. Y. Saleem, M. Mudassar, and K. Haider, "Implementation of the novel temperature controller and incremental conductance MPPT algorithm for indoor photovoltaic system," Solar Energy, vol. 163, pp. 235-242, March 2018.

[7] M. Kamran, M. Bilal and Z. Zeeshanjahan, "LabVIEW based simulator for solar cell characteristics and MPPT under varying atmospheric conditions," Mehran University Research Journal of Engineering and Technology, vol. 37, no. 3, pp. 529-538, July 2018.

[8] A. Dolara, R. Faranda, and S. Leva, "Energy comparison of seven MPPT techniques for PV systems," Journal of Electromagnetic Analysis and Applications, vol. 1, no. 3, pp. 152-162, January 2009.

[9] A. Attou, A. Massoum, and M. Saidi, "Photovoltaic power control using MPPT and boost converter," Balkan Journal of Electrical \& Computer Engineering, vol. 2, no. 1, pp. 23-27, September 2014.

[10] D. Choudhary and A. R. Saxena, "DC-DC buck-converter for MPPT of PV system," International Journal of Emerging Technology and Advanced Engineering, vol. 4, no. 7, pp. 813-821, July. 2014.

[11] N. Karami, N. Moubayed, and R. Outbib, "General review and classification of different MPPT techniques," Renewable and Sustainable Energy Reviews, vol. 68, pp. 1-18, February 2017.

[12] M. Bachar, A. Naddami, S. Hayani, and A. Fahli, "Optimization of pv panel using P\&O and incremental conductance algorithms for desalination mobile unit," Advanced Intelligent Systems Applied to Energy, vol. 2, pp. 164-184, January 2019.

[13] M. S. Reddy and P. V. R. Rao, "Fast tracking MPPT for photo voltaic system using ANFIS control logic ALgorithm," International Journal of Innovation Research in Science, Engineering and Technology, vol. 6, no. 3, pp. 3717-3726, March 2007. 
[14] K. Ishaque, Z. Salam, and G. Lauss, "The performance of perturb and observe and incremental conductance maximum power point tracking method under dynamic weather conditions," Journal of Applied Energy, vol. 119, pp. 228-236, April 2014.

[15] M. S. Reddy and P. V. R. Rao, "Fast tracking MPPT for photo voltaic system using ANFIS control logic algorithm," International Journal of Innovation Research in Science, Engineering and Technology, vol. 6, no. 3, pp. 3717-3726, March 2007.

[16] M. Bachar, A. Naddami, S. Hayani, and A. Fahli, "Design and dimensioning of desalination mobile unit and optimization of electrical energy with MPPT algorithms," Proc. Americain Institut of Physics, 2018.

[17] M. R. Kumar, S. S. Narayana, and G. Vulasala, "Advanced sliding mode control for solar PV array with fast voltage tracking for MPP algorithm,” International Journal of Ambient Energy, pp. 1-9, July 2018.

[18] S. E. Babaa, M. Armstrong, and V. Pickert, "Overview of maximum power point tracking control methods for PV systems,” Journal of Power and Energy Engineering, vol. 2, pp. 59-72, January 2014.

[19] M. Bachar, A. Naddami, and A. Fahli, "Photovoltaic power control using fuzzy logic and fuzzy logic type 2 MPPT algorithms and buck converter," Advances in Technology Innovation, vol. 4, no. 3, pp. 59-72, May 2019.

[20] M. Kermadi and E. M. Berkouk, "Artificial intelligence-based maximum power point tracking controllers for photovoltaic systems: comparative study,” Renewable and Sustainable Energy Reviews, vol. 69, pp. 369-386, March 2017.

[21] M. A. M. Ramli, S. Twaha, K. Ishaque, and Y. A. Al-Turki, “A review on maximum power point tracking for photovoltaic systems with and without shading conditions," Renewable and Sustainable Energy Reviews, vol. 67, pp. 144-159, January 2017.

[22] A. P. K. Yadav, S. Thirumaliah, and G. Haritha, "Comparison of MPPT Algorithms for DC-DC converters-based PV systems," International Journal of Advanced Research in Electrical, Electronics and Instrumentation Engineering, vol. 1, no. 1, pp. 18-23, January 2012.

[23] R. K. Kharb, S. L. Shimi, S. Chatterji, and M. F. Ansari, "Modeling of solar PV module and maximum power point tracking using ANFIS,” Renewable and Sustainable Energy Reviews, vol. 33, pp. 602-612, May 2014.

[24] E. H. Mamdani and S. Assilian, “An experiment in linguistic synthesis with a fuzzy logic controller”, International Journal of Man-Machine Studies, vol. 7, pp.1-13, January 1995.

Copyright $\odot$ by the authors. Licensee TAETI, Taiwan. This article is an open access article distributed under the terms and conditions of the Creative Commons Attribution (CC BY-NC) license (https://creativecommons.org/licenses/by-nc/4.0/). 